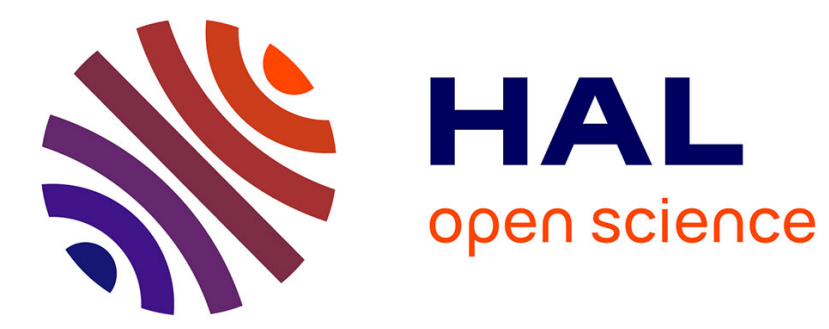

\title{
Net survival in recurrence-free colon cancer patients
} Antoine Drouillard, Anne-Marie Bouvier, Olayidé Boussari, Gaëlle Romain, Sylvain Manfredi, Come Lepage, Jean Faivre, Valérie Jooste

\section{To cite this version:}

Antoine Drouillard, Anne-Marie Bouvier, Olayidé Boussari, Gaëlle Romain, Sylvain Manfredi, et al.. Net survival in recurrence-free colon cancer patients. Cancer Epidemiology, 2019, 61, pp.124 - 128. 10.1016/j.canep.2019.06.001 . hal-03485853

\section{HAL Id: hal-03485853 \\ https://hal.science/hal-03485853}

Submitted on 20 Dec 2021

HAL is a multi-disciplinary open access archive for the deposit and dissemination of scientific research documents, whether they are published or not. The documents may come from teaching and research institutions in France or abroad, or from public or private research centers.
L'archive ouverte pluridisciplinaire HAL, est destinée au dépôt et à la diffusion de documents scientifiques de niveau recherche, publiés ou non, émanant des établissements d'enseignement et de recherche français ou étrangers, des laboratoires publics ou privés.

\section{다)(1) $(5$}

Distributed under a Creative Commons Attribution - NonCommerciall 4.0 International 


\section{Net survival in recurrence-free colon cancer patients}

Antoine Drouillard MD, Anne-Marie Bouvier MD PhD, Olayidé Boussari PhD, Gaëlle Romain, Sylvain Manfredi MD PhD, Come Lepage MD PhD, Jean Faivre MD PhD, Valérie Jooste PhD.

Digestive Cancer Registry of Burgundy, Dijon, France; LNC UMR1231 EPICAD, Dijon, France; Dijon University Hospital; University of Bourgogne Franche-Comté

Corresponding author: Valérie Jooste ; Digestive Cancer Registry of Burgundy; UFR des sciences de santé BP 87900; 21079 Dijon cedex; France

Telephone: +33 380393325 E-mail address: valerie.jooste@u-bourgogne.fr

Short Title: Survival in recurrence-free colon cancer

Abbreviations: CNS-RF: Conditional Net Survival in Recurrence-Free patients

Funding: The Registry is supported by the French Public Health Institute $(\mathrm{SpF})$ and the National Cancer Institute (INCa)

Disclaimer: None of the authors have any conflicts of interest to declare regarding this study.

\section{Word count: 2662}

\section{Authors' Contributions:}

Study concept and design: Dr. Antoine Drouillard, Dr. Anne Marie Bouvier, Pr. Côme Lepage, Pr. Jean Faivre and Dr. Valerie Jooste.

Acquisition, analysis, and interpretation of data: Dr. Drouillard Antoine, Gaelle Romain, Dr. Olayidé Boussari and Dr. Valerie Jooste.

Writing and critical revision of the manuscript: All authors.

\section{Highlights:}

Conditional net survival for recurrence-free cancer survivors (CNS-RF) is innovative.

It allows clinicians providing objective reassuring information to patients.

Whatever the stage at diagnosis, 5-year CNS-RF was > 90\% for colon cancer patients.

It was $>95 \%$ in patients diagnosed after 2000 and recurrence-free after 3 years.

This should be used to facilitate access to credit or insurance for cancer survivors. 


\begin{abstract}
Purpose: Conditional net survival in recurrence-free patients (CNS-RF) provides relevant clinical information and has never been assessed yet in a non-selected colon cancer population. We aimed to estimate conditional 5-year net survival in recurrence-free patients with colon cancer in the population-based Digestive Cancer Registry of Burgundy (France).
\end{abstract}

Methods: CNS-RF was estimated in the 3,736 patients resected for cure for primary colon cancer between 1976 and 2006, using a flexible parametric model of net survival for every additional year survived at diagnosis and from 1 to 5 years thereafter.

Results: The net probability of surviving 5 more years increased from $72 \%$ at diagnosis to $92 \%$ for recurrence-free patients who survived 5 years after diagnosis. CNS-RF was over $90 \%$ 3 years after diagnosis in patients aged 75 and below. CNS-RF was over 95\% in patients diagnosed after 2000 who were recurrence-free 3, 4 or 5 years after diagnosis. CNS-RF was similar between patients with stage I and II disease from 2 years after diagnosis and patients with stage III disease from 5 years after diagnosis. The initial differences in net survival related to gross features, clinical presentation, number of harvested nodes in stage II, and number of involved nodes in stage III disappeared after 2 years.

Conclusions: CNS-RF is a relevant measure of prognosis in patients who have already achieved a period of remission. Providing an updated estimation of prognosis in the years following diagnosis may improve the survivors' quality of life and access to credit or insurance.

Keywords: Colon cancer; Conditional net survival; Recurrence-free; Population-based study; Cancer registry 


\section{INTRODUCTION}

Colon cancer is a major public health problem. Approximately 30,000 new cases occur each year in France [1]. Complete surgical resection of the tumor, possibly completed with adjuvant treatments, is the reference treatment for colon cancer with curative intent. Although $35 \%$ of patients experience relapse, mostly during the first 5 years after diagnosis $[2,3]$, most patients undergoing curative resection achieve remission. Survival is generally reported from the time of cancer diagnosis. Evaluating the changing risk of death in the successive years following the diagnosis provides important information for cancer survivors and clinicians. Conditional survival is estimated from the probability of death, conditional on having survived until then, and it measures the dynamics of this probability over time. Populationbased cancer registries are ideally suited to provide unbiased and representative estimates of survival [4] . Net survival, which corresponds to the survival that would be observed if patients could not die from a cause other than the cancer studied, provides useful information, especially for geographical or calendar comparisons. Conditional net survival for colon cancer based on cancer registry data has already been published [4-6] . However, the population alive at a certain time after diagnosis is heterogeneous, as it includes both patients with recurrent disease and recurrence-free patients. Determining whether a patient is recurrence-free over time after the diagnosis requires the active participation of clinicians, which is difficult to achieve for many cancer registries. For this reason, no previous study has assessed CNS-RF in a general population with colon cancer. The aim of this study was to measure 5-year net survival conditional on being recurrence free (CNS-RF) at varying intervals from 1 to 5 years after diagnosis in a nonselected French population of patients with colon cancer.

\section{PATIENTS AND METHODS}




\section{Patients}

All colon cancers diagnosed in a French administrative area (Côte-d'Or, Burgundy) have been recorded since 1976 by a population-based digestive cancer registry. Data were actively collected from multiple sources: public and private pathology laboratories, university hospitals (including the cancer centers), general hospitals, private specialists (gastroenterologists, surgeons, medical oncologists, and radiotherapists), hospital administrative databases, the Regional Health Service database and death certificates. Patients treated outside the area were identified through the National Health Service database. Registration quality and exhaustiveness are certified every four years by an audit performed through the Registries Evaluation Committee by the National Cancer Institute (INCa), the National Institute for Health and Medical Research (INSERM) and the National Public Health Institute $(\mathrm{SpF})$.

Colon cancers were defined according to the International Classification of Diseases for Oncology, $3^{\text {rd }}$ revision (ICD-0-3, C18) [7] . From 1976 to 2006, 4,147 nonmetastatic invasive adenocarcinoma colon cancers were registered by the Digestive Cancer Registry of Burgundy. Patients with other synchronous cancers at diagnosis $(\mathrm{N}=129)$, patients who did not undergo curative resection $(\mathrm{N}=275)$, and patients with an unknown vital status $(\mathrm{n}=7)$ were excluded.

Information on recurrences (i.e., local recurrence or distant metastasis) over the 5 years following diagnosis was obtained from all clinicians involved in the management and followup of the patients. A questionnaire was sent to general practitioners to determine whether relapse occurred. In the absence of response (nearly $30 \%$ of the questionnaires), the specialists (gastroenterologist, surgeon or oncologist) who managed the patient were contacted. Information on recurrence was available for $93 \%$ of the studied population 5 years after diagnosis of the primary tumor. 


\section{Collected data}

Information on age, sex and stage at diagnosis was routinely collected. The period of diagnosis was divided into four periods: 1976-1983, 1984-1991, 1992-1999 and 2000-2006. Patients were categorized into three age groups: under 65 years, 65-74 years and over 75 years. Stage at diagnosis was classified according to the TNM classification [8] : stage I (T1/2, N0, M0), stage II (T3/4, N0, M0), and stage III (all T, N1/3, M0). For stage II cases, the number of harvested lymph nodes was categorized into two groups: $<12$ nodes and $\geq 12$ nodes. For stage III cases, the number of involved nodes was categorized as <4 nodes (N1) and $\geq 4$ nodes $(\mathrm{N} 2 / \mathrm{N} 3)$. Clinical presentation was separated into emergency (obstruction or perforation) or scheduled resection. According to macroscopic gross features, tumors were classified as fungating or ulcero-infiltrative.

\section{Statistical analyses}

Net survival is defined as the survival that would be observed if cancer was the only cause of death $[9,10]$. It can be estimated without knowledge of the cause of death using excess mortality rate methodology [11] . For a given patient, the observed mortality rate is defined as the sum of the expected mortality rate (in a group of persons from the general population sharing the same demographic characteristics with the considered patient) and the excess mortality rate. The expected mortality rate is derived from life tables (provided by the INSEE, Institut National de la Statistique et des Etudes Economiques) according to sex, age and year of death. Five-year net survival was estimated using a flexible parametric model of the cumulative excess mortality rate $[12,13]$ adjusted for sex, age at diagnosis and year of diagnosis.

Five-year net survival conditional on the absence of recurrence (CNS-RF) was defined as the $(x+5)$-year net survival of recurrence-free survivors $x$ years after diagnosis. This expanded definition of conditional survival could not be directly calculated from net survival estimates 
because recurrence was neither considered as an event nor censored in the net survival analysis. As proposed by Zamboni et al [14], the condition relied on the "conditioning set of patients", in our study alive and free of recurrence. CNS-RF was estimated six times by

allowing $x$ to vary from $t 0=0$ to $t 0=5$ years after diagnosis. For each $t 0$, patients who had undergone death or recurrence prior to t0 were removed from the dataset. For each t0, the follow-up was censored at t0+5 years, 5-year net survival was estimated through a net survival model and factors associated with CNS-RF were assessed using a multivariate net survival model. The likelihood ratio test was performed to assess the effect of each factor. Separate analyses were carried out for TNM stage II and stage III colon cancers because the explanatory factors partially differed.

The analyses were performed using STATA, release 14 (STATA, College Station, TX, USA). Significance was defined as a p-value $<0.05$.

\section{RESULTS}

In this study, 3736 patients were considered. There was a slight male predominance (ratio $\mathrm{M} / \mathrm{F}=1.10$ ). Between the periods 1976-1983 and 2000-2006, the proportion of patients over 75 years increased from $35 \%$ to $43 \%$ ( $\mathrm{p}<0.001)$. The proportions of patients according to disease stage for the two periods, respectively, were as follows: stage I, $21 \%$ and $24 \%$; stage II, $52 \%$ and $45 \%$; and stage III, $27 \%$ and $31 \%$ (NS). The proportions of cancers diagnosed in the context of an emergency were $12 \%$ and $11 \%(\mathrm{NS})$, respectively.

Table 1 presents the 5-year net survival at diagnosis and CNS-RF at t0 varying from 1 to 5 years after diagnosis according to sex, age group, TNM stage, gross features, presentation, number of harvested nodes in stage II and number of involved nodes in stage III. Overall, the net probability of surviving 5 more years increased from $72 \%$ at diagnosis $(\mathrm{t} 0=0)$ to $92 \%$ for patients who survived 5 years after diagnosis without recurrence $(\mathrm{t} 0=5)$. No substantial 
difference in CNS-RF was observed between males and females, regardless of t0. The 5-year net survival at diagnosis varied between $73 \%$ in patients under 65 years and $64 \%$ in those aged 75 or more $(\mathrm{p}<0.001)$. Patients in different age groups who survived 1 year after diagnosis had a similar CNS-RF. The CNS-RF stabilized in patients aged 75 and over, while it continued to improve in patients under 75 , reaching more than $90 \%$ at 3 years after diagnosis. Five years after diagnosis, CNS-RF varied between $83 \%$ ( $\geq 75$ years) and $94 \%$ (6574 years, $\mathrm{p}=0.015$ ). CNS-RF increased over the periods of diagnosis and reached $95 \%$ during the period 2000-2006 in survivors who were recurrence-free 3, 4 and 5 years after diagnosis. The 5-year net survival at the time of diagnosis was lower in patients diagnosed in the context of an emergency than in those who underwent scheduled surgery (53\% vs $74 \%, \mathrm{p}<0.001)$. Two years after diagnosis, the gap between the two groups had disappeared. Similarly, survival in patients with fungating tumors was initially better than that in patients with ulceroinfiltrative tumors. After 2 years, the gross features were no longer a prognostic factor. An advanced stage at diagnosis significantly worsened net survival (90\% for stage I, $76 \%$ for stage II and 52\% for stage III, $\mathrm{p}<0.001)$. This gap decreased over time. For patients with stage I disease who already had a high survival expectancy at diagnosis, the CNS-RF remained stable at approximately $90 \%$ regardless of the t0. In stage II patients, CNS-RF became similar to that in stage I patients from 2 years after diagnosis onward. Stage III was no longer a factor associated with a poor prognosis in patients alive and free of recurrence 5 years after diagnosis.

In stage II patients, the 5-year net survival at diagnosis in those with fewer than 12 harvested lymph nodes (35\% of the cases) was worse than that in patients with at least 12 harvested nodes (Table 1). As time elapsed from diagnosis, CNS-RF improved and the gap between the two groups decreased. There was no longer a difference in CNS-RF between the two groups 2 years after diagnosis. 
In stage III patients with $\mathrm{N} 2 / \mathrm{N} 3$ extension ( $23 \%$ of the cases), the 5-year net survival at diagnosis was lower than that in stage III patients with N1 extension (Table 1). The gap between the two groups narrowed and was no longer significant 2 years after diagnosis.

Multivariate analyses were conducted, adjusting for sex, age and period of diagnosis, separately for stage II (Table 2) and stage III (Table 3). In stage II patients, the number of harvested nodes, gross features and presentation were significant prognostic factors at diagnosis. None of these factors were associated with CNS-RF after 2 years. In stage III patients, the number of involved nodes and gross features were significant prognostic factors at diagnosis, whereas presentation was not. The number of involved nodes remained a factor associated with poor prognosis in recurrence-free patients 1 year after diagnosis. None of the studied factors were associated with CNS-RF after 2 years.

\section{DISCUSSION}

Our main finding was that in patients with colon cancer, the additional 5-year net survival increased markedly as recurrence-free time elapsed. CNS-RF, the survival probability for patients who have survived free of recurrence for a certain period of time, provides relevant information to physicians and cancer survivors. Initial differences in net survival related to age, stage, gross features, clinical presentation, number of harvested nodes in stage II, and number of involved nodes in stage III decreased over time after diagnosis in patients in remission. In patients aged 75 and over, CNS-RF remained lower than that in younger patients up to 5 years after diagnosis. For survivors who had been in remission for at least 3 years after diagnosis, it increased from $83 \%$ in $1976-1983$ to $96 \%$ in $2000-2006$. A probable explanation for this increase is the improvement in surveillance techniques and treatment. Furthermore, in stage III, CNS-RF was over $90 \%$ and became similar to that in stage I only 5 
years after diagnosis. Our study showed that among all the factors with prognostic value at diagnosis, only age and stage remained prognostic factors beyond two years after diagnosis.

In France, in 2015, the obligation to declare a cancer was rescinded if 10 years had passed since the end of treatment, thus suppressing the surtax applied to cancer survivors for insurance and credit. This law was a major improvement for society. This time period could, however, be shortened for certain cancer sites by using the time to statistical cure, which can be estimated by the time at which conditional net survival reaches 95\% [15]. Applying this definition to CNS-RF, patients diagnosed with colon cancer in the last period who are alive and recurrence-free 3 years after diagnosis can be considered statistically cured, as excess mortality due to cancer is insignificant. Survival in these patients is thus comparable to that in anyone from the general population with similar demographic characteristics. Such survivors should therefore be entitled to surtax-free insurance or credit 3 years after diagnosis if no recurrence has occurred. Similar analyses must be conducted for other cancer sites.

To our knowledge, this study is the first population-based study reporting 5-year net survival conditional on the absence of recurrence in patients with colon cancer for every additional year after diagnosis from 1 to 5 years. Publications related to disease-free survival after primary cancer are scarce [16-18]. Only one publication estimated overall survival conditional to recurrence. It concerned colon cancer and relied on data from clinical trials [14]. Estimations from hospital databases or clinical trials cannot be regarded as a reference because of unavoidable selection bias. Population-based studies provide unbiased indicators, but detailed information on cancer recurrence at the population level is rarely available. This study demonstrated the feasibility of estimating CNS-RF at the population level. The active clinical follow-up, the large size of the cohort and the use of a flexible parametric model of net survival strengthened the reliability and widened the scope of our results. There is 
increasing interest in cancer registries for this type of information, and, in the future, highresolution studies may provide data on recurrence, making CNS-RF comparisons possible.

There are some limitations of this study. As time elapsed from diagnosis, an increasing number of patients developed recurrences or died. Those patients were removed from the dataset at each $\mathrm{t} 0$, decreasing the size of the iterative datasets. As a consequence, some analyses relied on small numbers of individuals. This limitation may have resulted in a failure to detect some associations over time. Moreover, extensive and long-standing observational population-based studies cannot include detailed data, such as comorbidities and lifestyle characteristics, throughout the follow-up of patients.

In conclusion, this study shows that conditional net survival of recurrence-free patients with colon cancer increases dramatically with the time since diagnosis. These results will help clinicians to provide potentially reassuring information to cancer survivors. Reporting the improvement in CNS-RF over time may reduce survivors' anxiety and may facilitate access to insurance and credit.

Acknowledgements: The authors thank all the private and public physicians, specialists and pathologists for their collaboration, the French Public Health Institute $(\mathrm{SpF})$, the National Cancer Institute (INCa) for supporting the Registry and Stéphanie Normand and Ludivine Garrier (Digestive Cancer Registry of Burgundy, France) for technical assistance.

\section{References}

[1] V. Jooste, L. Remontet, M. Colonna, A. Belot, G. Launoy, F. Binder, J. Faivre, A.M. Bouvier, Trends in the incidence of digestive cancers in France between 1980 and 2005 and projections for the year 2010, Eur J Cancer Prev. 20 (2011) 375-80. 
[2] S. Manfredi, A.M. Bouvier, C. Lepage, C. Hatem, V. Dancourt, J. Faivre, Incidence and patterns of recurrence after resection for cure of colonic cancer in a well defined population, Br J Surg. 93 (2006) 1115-22.

[3] V. Jooste, P. Grosclaude, L. Remontet, G. Launoy, I. Baldi, F. Molinie, P. Arveux, N. Bossard, A.M. Bouvier, M. Colonna, Unbiased estimates of long-term net survival of solid cancers in France, Int J Cancer. 132 (2013) 2370-7.

[4] A. Drouillard, A.M. Bouvier, F. Rollot, J. Faivre, V. Jooste, C. Lepage, Conditional net survival: Relevant prognostic information for colorectal cancer survivors. A French population-based study, Dig Liver Dis. 47 (2015) 597-601.

[5] F.N. van Erning, L.N. van Steenbergen, V. Lemmens, H.J.T. Rutten, H. Martijn, D.J. van Spronsen, M.L.G. Janssen-Heijnen, Conditional survival for long-term colorectal cancer survivors in the Netherlands: who do best?, Eur J Cancer. 50 (2014) 1731-1739.

[6] Y. Ito, I. Miyashiro, H. Ito, S. Hosono, D. Chihara, K. Nakata-Yamada, M. Nakayama, M. Matsuzaka, M. Hattori, H. Sugiyama, I. Oze, R. Tanaka, E. Nomura, Y. Nishino, T. Matsuda, A. loka, H. Tsukuma, T. Nakayama, Long-term survival and conditional survival of cancer patients in Japan using populationbased cancer registry data, Cancer Sci. 105 (2014) 1480-6.

[7] A. Fritz, C. Percy, A. Jack, K. Shanmugaratnam, H. Sobin, International classification of diseases for oncology. 3rd ed. World Health Organization. http://www.who.int/iris/handle/10665/42344 (accessed 17/05/2019), (2000).

[8] L. Sobin, M. Gospodarowicz, C. Wittekind, TNM classification of malignant tumours. 7th ed, (2009).

[9] K.A. Cronin, E.J. Feuer, Cumulative cause-specific mortality for cancer patients in the presence of other causes: a crude analogue of relative survival, Stat Med. 19 (2000) 1729-40.

[10] P.C. Lambert, P.W. Dickman, M.J. Rutherford, Comparison of different approaches to estimating age standardized net survival, BMC Med Res Methodol. 15 (2015) 64.

[11] J. Esteve, E. Benhamou, M. Croasdale, L. Raymond, Relative survival and the estimation of net survival: elements for further discussion, Stat Med. 9 (1990) 529-38.

[12] C.P. Nelson, P.C. Lambert, I.B. Squire, D.R. Jones, Flexible parametric models for relative survival, with application in coronary heart disease, Stat Med. 26 (2007) 5486-98. 
[13] P. Royston, M.K. Parmar, Flexible parametric proportional-hazards and proportional-odds models for censored survival data, with application to prognostic modelling and estimation of treatment effects, Stat Med. 21 (2002) 2175-97.

[14] B.A. Zamboni, G. Yothers, M. Choi, C.D. Fuller, J.J. Dignam, P.C. Raich, C.R. Thomas, Jr., M.J. O'Connell, N. Wolmark, S.J. Wang, Conditional survival and the choice of conditioning set for patients with colon cancer: an analysis of NSABP trials C-03 through C-07, J Clin Oncol. 28 (2010) 2544-8.

[15] L. Dal Maso, S. Guzzinati, C. Buzzoni, R. Capocaccia, D. Serraino, A. Caldarella, A.P. Dei Tos, F. Falcini, M. Autelitano, G. Masanotti, S. Ferretti, F. Tisano, U. Tirelli, E. Crocetti, R. De Angelis, Longterm survival, prevalence, and cure of cancer: a population-based estimation for 818902 Italian patients and 26 cancer types, Ann Oncol. 25 (2014) 2251-60.

[16] M.L. Kurta, R.P. Edwards, K.B. Moysich, K. McDonough, M. Bertolet, J.L. Weissfeld, J.M. Catov, F. Modugno, C.H. Bunker, R.B. Ness, B. Diergaarde, Prognosis and conditional disease-free survival among patients with ovarian cancer, J Clin Oncol. 32 (2014) 4102-12.

[17] H.J. Paik, S.K. Lee, J.M. Ryu, S. Park, I. Kim, S.Y. Bae, J. Yu, J.E. Lee, S.W. Kim, S.J. Nam, Conditional disease-free survival among patients with breast cancer, Medicine (Baltimore). 96 (2017) e5746.

[18] L.E. Haydu, R.A. Scolyer, S. Lo, M.J. Quinn, R.P.M. Saw, K.F. Shannon, A.J. Spillane, J.R. Stretch, W.H. McCarthy, J.F. Thompson, Conditional Survival: An Assessment of the Prognosis of Patients at Time Points After Initial Diagnosis and Treatment of Locoregional Melanoma Metastasis, J Clin Oncol. 35 (2017) 1721-1729. 
Table 1: Five-year net survival ${ }^{\$}$ after colon cancer diagnosis, conditional on being alive free of recurrence $1,2,3,4$ or 5 years after diagnosis

\begin{tabular}{|c|c|c|c|c|c|c|c|c|c|c|c|c|c|c|c|c|c|c|c|}
\hline \multirow[b]{3}{*}{ Overall } & \multirow{3}{*}{$\begin{array}{c}\begin{array}{c}\mathrm{N} \text { at } \\
\text { diagnosis }\end{array} \\
\mathbf{3 7 3 6}\end{array}$} & \multirow{2}{*}{\multicolumn{2}{|c|}{$\begin{array}{c}\text { 5-year Net } \\
\text { Survival }\end{array}$}} & \multirow{3}{*}{$\mathbf{P}^{\$}$} & \multicolumn{15}{|c|}{ 5-year net survival conditional on being alive free of recurrence five years after $t_{0},[95 \% \mathrm{CI}], \mathrm{p}^{\$}$} \\
\hline & & & & & \multicolumn{3}{|c|}{$\begin{array}{c}\mathbf{t}_{0}=1 \text { year after } \\
\text { diagnosis }\end{array}$} & \multicolumn{3}{|c|}{$\begin{array}{c}\mathbf{t}_{0}=2 \text { years after } \\
\text { diagnosis }\end{array}$} & \multicolumn{3}{|c|}{$\begin{array}{c}\mathbf{t}_{0}=3 \text { years after } \\
\text { diagnosis }\end{array}$} & \multicolumn{3}{|c|}{$\begin{array}{c}\mathrm{t}_{0}= \\
\begin{array}{c}\text { years after } \\
\text { diagnosis }\end{array}\end{array}$} & \multicolumn{3}{|c|}{$\begin{array}{c}\mathbf{t}_{0}=5 \text { years after } \\
\text { diagnosis }\end{array}$} \\
\hline & & $72 \%$ & [70-73] & & $80 \%$ & [78-82] & & $86 \%$ & [84-88] & & $90 \%$ & {$[87-92]$} & & $91 \%$ & [89-93] & & $92 \%$ & [90-94] & \\
\hline \multicolumn{20}{|l|}{ Age at diagnosis } \\
\hline$<65$ years & 1061 & $73 \%$ & [70-76] & \multirow{3}{*}{$<0.001$} & $80 \%$ & [77-83] & \multirow{3}{*}{0.605} & $88 \%$ & [85-90] & \multirow{3}{*}{0.189} & $91 \%$ & [88-93] & \multirow{3}{*}{0.033} & $93 \%$ & [89-95] & \multirow{3}{*}{0.040} & $93 \%$ & [87-96] & \multirow{3}{*}{0.015} \\
\hline $65-74$ years & 1103 & $77 \%$ & [74-80] & & $80 \%$ & [76-83] & & $87 \%$ & [83-90] & & $90 \%$ & [86-93] & & $92 \%$ & [86-95] & & $94 \%$ & [91-96] & \\
\hline$\geq 75$ years & 1572 & $64 \%$ & [61-68] & & $78 \%$ & [73-82] & & $83 \%$ & [77-87] & & $83 \%$ & [77-88] & & $84 \%$ & [76-89] & & $83 \%$ & [74-89] & \\
\hline \multicolumn{20}{|l|}{ Sex } \\
\hline Male & 1958 & $73 \%$ & [70-75] & \multirow{2}{*}{0.283} & $79 \%$ & [76-82] & \multirow{2}{*}{0.734} & $86 \%$ & [83-89] & \multirow{2}{*}{0.781} & $88 \%$ & [85-91] & \multirow{2}{*}{0.391} & $90 \%$ & [86-92] & \multirow{2}{*}{0.090} & $91 \%$ & [87-94] & \multirow{2}{*}{0.116} \\
\hline Female & 1778 & $71 \%$ & [68-73] & & $80 \%$ & [77-83] & & $86 \%$ & [83-89] & & $91 \%$ & [88-93] & & $93 \%$ & [89-95] & & $94 \%$ & [90-96] & \\
\hline Period & & & & & & & & & & & & & & & & & & & \\
\hline 1976-1983 & 674 & $61 \%$ & [57-66] & & $73 \%$ & [68-78] & & $81 \%$ & [76-86] & & $83 \%$ & [77-88] & & $86 \%$ & [78-90] & & $91 \%$ & [83-95] & \\
\hline 1984-1991 & 964 & $64 \%$ & [60-67] & $<0001$ & $72 \%$ & [68-77] & $<0001$ & $81 \%$ & [76-85] & $<0001$ & $\mathbf{8 8 \%}$ & [82-92] & $<0001$ & $90 \%$ & [84-94] & 0006 & $91 \%$ & [85-94] & 0177 \\
\hline 1992-1999 & 1052 & $74 \%$ & [70-77] & $<0.001$ & $81 \%$ & [77-84] & $<0.001$ & $86 \%$ & [82-89] & $<0.001$ & $87 \%$ & [83-91] & $<0.001$ & $90 \%$ & [85-94] & 0.000 & $92 \%$ & [87-96] & 0.171 \\
\hline Gross features* & & & & & & & & & & & & & & & & & & & \\
\hline Fungating & 2321 & $77 \%$ & [74-79] & $<0001$ & $72 \%$ & [69-76] & $<0001$ & $84 \%$ & [80-88] & 0170 & $88 \%$ & [84-91] & 0374 & $90 \%$ & [85-94] & 0544 & $93 \%$ & [90-95] & 0466 \\
\hline Ulcero-infiltrative & 1344 & $62 \%$ & [59-65] & $<0.001$ & $83 \%$ & [81-85] & $<0.001$ & $87 \%$ & [84-89] & $0.1 / 9$ & $90 \%$ & [87-92] & $0.3 / 4$ & $92 \%$ & [89-94] & 0.544 & $91 \%$ & [86-95] & 0.466 \\
\hline Resection* & & & & & & & & & & & & & & & & & & & \\
\hline Scheduled & 3241 & $74 \%$ & [72-76] & $<0001$ & $81 \%$ & [79-83] & $<0001$ & $87 \%$ & [84-89] & 0171 & $90 \%$ & [87-92] & 0280 & $92 \%$ & [89-94] & 0147 & $93 \%$ & [91-95] & ? \\
\hline Emergency & 453 & $\mathbf{5 3 \%}$ & {$[47-58]$} & $<0.001$ & $69 \%$ & [62-75] & 0.001 & $82 \%$ & [74-88] & 0.171 & $86 \%$ & [77-92] & 0.380 & $86 \%$ & [75-92] & 0.147 & $85 \%$ & [74-92] & 0.042 \\
\hline Stage TNM & & & & & & & & & & & & & & & & & & & \\
\hline I & 803 & $90 \%$ & [87-93] & & $92 \%$ & [88-95] & & $91 \%$ & [87-94] & & $92 \%$ & [87-95] & & $91 \%$ & [86-94] & & $91 \%$ & [86-94] & \\
\hline II & 1805 & $76 \%$ & [73-78] & $<0.001$ & $84 \%$ & [81-87] & $<0.001$ & $89 \%$ & [86-92] & $<0.001$ & $93 \%$ & [89-95] & $<0.001$ & $94 \%$ & [90-97] & 0.009 & $94 \%$ & [90-96] & 0.347 \\
\hline III & 1128 & $52 \%$ & [49-56] & & $61 \%$ & [57-65] & & $75 \%$ & [71-80] & & $82 \%$ & [76-86] & & $86 \%$ & {$[80-90]$} & & $92 \%$ & [86-95] & \\
\hline Number of harves & odes in stag & II* $^{*}$ & & & & & & & & & & & & & & & & & \\
\hline$<12$ nodes & 1168 & $71 \%$ & [67-74] & & $81 \%$ & [77-84] & & $85 \%$ & [81-89] & & $90 \%$ & [84-93] & & $93 \%$ & [87-96] & & $91 \%$ & [85-95] & \\
\hline$\geq 12$ nodes & 623 & $83 \%$ & [79-87] & $<0.001$ & $90 \%$ & [85-93] & 0.001 & $95 \%$ & [90-97] & 0.007 & $96 \%$ & [90-99] & 0.052 & $96 \%$ & [89-98] & 0.214 & $97 \%$ & [89-99] & 0.123 \\
\hline Number of involve & des in stage & & & & & & & & & & & & & & & & & & \\
\hline$<4$ nodes & 868 & $56 \%$ & {$[52-60]$} & & $63 \%$ & [58-67] & & $75 \%$ & {$[70-80]$} & & $81 \%$ & {$[75-85]$} & & $86 \%$ & [80-90] & & $93 \%$ & [86-96] & \\
\hline
\end{tabular}


Table 2: TNM stage II colon cancer: Factors associated with 5-year net survival among patients alive and free of recurrence at to after diagnosis (multivariable analyses ${ }^{\S}$ )

\begin{tabular}{cccccc} 
HR [95\% CI $]$ & HR $[95 \% \mathrm{CI}]$ & HR $[95 \% \mathrm{CI}]$ & HR $[95 \% \mathrm{CI}]$ & HR $[95 \% \mathrm{CI}]$ & HR $[95 \% \mathrm{CI}]$ \\
& $\mathbf{t}_{0}=1$ year & $\mathbf{t}_{0}=2$ years & $\mathbf{t}_{0}=3$ years & $\mathbf{t}_{0}=4$ years & $\mathbf{t}_{0}=5$ years \\
$\mathbf{t}_{0}=$ diagnosis & after diagnosis & after diagnosis & after diagnosis & after diagnosis & after diagnosis \\
\hline
\end{tabular}

\section{Number of}

harvested nodes*

$<12$ nodes

$\geq 12$ nodes

$\begin{array}{ll}1 & 1 \\ \mathbf{0 . 7 4}[0.56-0.97] & \mathbf{0 . 5 9}[0.37-0.94] \\ \mathrm{p}=0.031 & \mathrm{p}=0.028\end{array}$

1
$\mathbf{0 . 5 0}[0.25-1.02]$
$\mathrm{p}=0.057$
1
$\mathbf{0 . 3 6}[0.11-1.17]$
$\mathrm{p}=0.09$

$\begin{array}{ll}1 & 1 \\ \mathbf{0 . 5 5}[0.15-2.06] & \mathbf{0 . 5 0}[0.15-1.62] \\ \mathrm{p}=0.375 & \mathrm{p}=0.247\end{array}$

\section{Gross feature*}

Fungating

Ulcero-infiltrative

$\begin{array}{ll}1 & 1 \\ \mathbf{1 . 3 1}[1.04-1.66] & \mathbf{1 . 2 0}[0.83-1.74] \\ \mathrm{p}=0.022 & \mathrm{p}=0.333\end{array}$

1

0.79 [0.46-1.36]

$\mathrm{p}=0.396$
1
0.77 [0.39-1.54]

$\mathrm{p}=0.461$

1

0.89 [0.39-2.06]

1 $\mathrm{p}=0.788$

$1.00[0.44-2.25]$

$\mathrm{p}=0.995$

\section{Resection*}

Scheduled

Emergency

$\begin{array}{lll}1 & 1 & 1 \\ \mathbf{2 . 3 3}[1.80-3.02] & \mathbf{1 . 7 3}[1.11-2.71] & \mathbf{1 . 6 8}[0.90-3.11] \\ \mathrm{p}<0.001 & \mathrm{p}=0.016 & \mathrm{p}=0.101\end{array}$

1

1.18 [0.47-2.95]

1 $\mathrm{p}=0.73$

$1.42[0.45-4.46]$ $\mathrm{p}=0.543$ $\mathrm{p}=0.506$

*Unknown at diagnosis: harvested nodes $=14$ cases, gross features $=29$ cases, resection $=20$ cases

${ }^{\S}$ Conditional net survival was modeled separately for each to using six multivariate flexible net survival models, each adjusted for the number of harvested nodes, gross features, presentation, sex, age at diagnosis and year of diagnosis; p-values were calculated using the likelihood ratio test 
Table 3: TNM stage III colon cancer: Factors associated with 5-year net survival among patients alive and free of recurrence at t0 after diagnosis (multivariable analyses ${ }^{\S}$ )

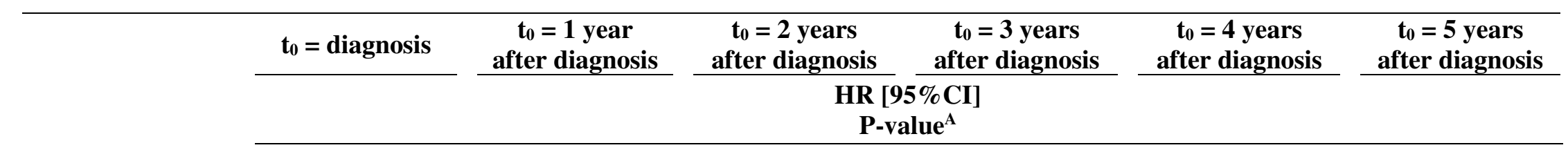

\section{Number of}

involved nodes*

$<4$ nodes

$\geq 4$ nodes

1
$\mathbf{2 . 0 1}[1.62-2.48]$
$\mathrm{p}<0.001$
1
$1.70[1.26-2.31]$
$\mathrm{p}=0.001$
$1.29[0.76-2.18]$
$\mathrm{p}=0.352$
1
$0.97[0.42-2.24$
$\mathrm{p}=0.944$
1
$1.12[0.39-3.22]$
$\mathrm{p}=0.837$

1

1.48 [0.36-6.13]

$\mathrm{p}=0.589$

Gross features *

Fungating

1

Ulcero-infiltrative

$$
\begin{gathered}
\mathbf{1 . 2 3}[1.01-1.50] \\
\mathrm{p}=0.037
\end{gathered}
$$

\section{1}

1.27 [0.98-1.65]

$\mathrm{p}=0.075$

\section{1}

$1.16[0.77-1.74]$

$\mathrm{p}=0.486$

1

$1.23[0.72-2.11]$

$\mathrm{p}=0.446$

1

$1.51[0.71-3.20]$

$\mathrm{p}=0.289$

1

\section{Resection*}

Scheduled

Emergency

$\begin{array}{cc}1 & 1 \\ \mathbf{1 . 2 4}[0.96-1.60] & \mathbf{0 . 9 1}[0.61-1.36] \\ \mathrm{p}=0.107 & \mathrm{p}=0.650\end{array}$

1

1

1

$\mathbf{0 . 7 4}[0.38-1.45] \quad \mathbf{0 . 9 2}[0.42-2.03] \quad \mathbf{1 . 0 5}[0.39-2.87] \quad \mathbf{1 . 9 5}[0.60-6.35]$ $\mathrm{p}=0.381$ $\mathrm{p}=0.839$ $\mathrm{p}=0.917$

\section{$1.67[0.54-5.21]$}

$\mathrm{p}=0.374$

*Unknown at diagnosis: number of lymph nodes involved $=4$ cases, gross features $=18$ cases, resection $=10$ cases ${ }^{\S}$ Conditional net survival was modeled separately for each

$t_{0}$ using six multivariate flexible net survival models, each adjusted for the number of involved nodes, gross features, presentation, sex, age at diagnosis and year of diagnosis; p-values were calculated using the likelihood ratio test 